\title{
Belgeo
}

Revue belge de géographie

3 | 2014

Art(s) \& Espace(s) / Art(s) \& Space(s)

\section{L'espace insulaire du carnaval des écoles de samba de Rio de Janeiro}

The insular space of Rio de Janeiro samba schools Carnival

Laura Jouve-Villard

\section{CpenEdition}

Journals

Édition électronique

URL : http://journals.openedition.org/belgeo/13245

DOI : 10.4000/belgeo.13245

ISSN : 2294-9135

Éditeur :

National Committee of Geography of Belgium, Société Royale Belge de Géographie

Référence électronique

Laura Jouve-Villard, «L'espace insulaire du carnaval des écoles de samba de Rio de Janeiro », Belgeo [En ligne], 3 | 2014, mis en ligne le 19 décembre 2014, consulté le 20 avril 2019. URL : http:// journals.openedition.org/belgeo/13245; DOI : 10.4000/belgeo.13245

Ce document a été généré automatiquement le 20 avril 2019

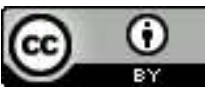

Belgeo est mis à disposition selon les termes de la licence Creative Commons Attribution 4.0 International. 


\title{
L'espace insulaire du carnaval des écoles de samba de Rio de Janeiro
}

The insular space of Rio de Janeiro samba schools Carnival

\author{
Laura Jouve-Villard
}

\section{En bordure de la Ville Merveilleuse}

1 L'annonce en octobre 2009 de la victoire de «la Ville Merveilleuse » à la sélection de la ville d'accueil des Jo 2016 a sonné le coup d'envoi d'une décennie méga-événementielle sans précédent en Amérique Latine (déjà introduite par les Jeux Panaméricains organisés à Rio en 2007). Rio+20 en 2012, les Journées Mondiales de la Jeunesse en 2013, la Coupe du Monde de Football en 2014, les Jeux Olympiques et Paralympiques en 2016: l'espace urbain carioca est actuellement scandé par de multiples projets de revitalisation, réhabilitation, régénération ou encore requalification destinés à « préparer Rio à recevoir le monde » comme l'annonçait l'ex-président brésilien Luiz Ignacio da Silva (dit « Lula ») le 2 octobre 2009, quelques heures avant la victoire de Rio, première ville du continent sud-américain à accueillir les Jeux Olympiques. Parmi les principales zones de la «territorialisation olympique » (Dansero et Mela, 2007) de « Rio2016», le Porto Maravilha, un vaste programme de rénovation de la zone portuaire, fait figure de modèle d'un développement urbain "durable» facilité dans sa réalisation par l'urgence que représente le rétro-planning méga-événementiel (Sanchez et Broudehoux, 2013). Dans les rues de ce port industriel qui souffrait de déshérence depuis les années 1960 (Magalhães, 2008), les images d'un futur en haute définition s'affichent sur les palissades des chantiers tandis que celles d'un passé en sépia escortent la construction de nouveaux «corridors culturels », sites archéologiques, musées et centres mémoriels, lieux de rencontres et d'innovations culturelles et scientifiques. L'aura de cette opération urbaine que le maire de Rio de Janeiro Eduardo Paes tient pour le plus grand leg que les cariocas garderont des Jeux Olympiques, tend à effacer de la scène médiatique locale et internationale d'autres quartiers de la ville qui expérimentent d'importants bouleversements infrastructurels, économiques et sociaux à l'approche de l'horizon 2016. 
2 La découpe administrative du cadastre urbain en morceaux de ville (quartiers, sousrégions, zones, blocs, communautés etc.) a ceci de surprenant qu'un territoire peut être totalement exclu de la pensée aménagiste tandis que moins de quarante mètres plus loin, il se retrouve sous les projecteurs du futur en marche. Le quartier du Sambódromo en est un exemple. Situé à deux cents mètres à l'extérieur de la frontière sud délimitant la zone administrative du Porto Maravilha, le Sambodrome est une avenue bordée de gradins de sept cents mètres de long et treize de large accueillant tous les ans le «Carnaval officiel de Rio de Janeiro ", c'est à dire le défilé compétitif des meilleures écoles de samba de la ville. Pendant les Jeux de 2016, il servira de lieu de départ et d'arrivée au marathon olympique, et accueillera les épreuves de tir à l'arc. Construit au cœur du quartier mythique de la Praça Onze, tenu pour être un des berceaux historiques de la samba et du carnaval, cet immense équipement scénique qui ne s'ouvre au public qu'une semaine par an peine à s'inscrire dans son quartier environnant.

Figure 1. Région Métropolitaine de Rio de Janeiro. Encadrée en rouge, la zone portuaire.

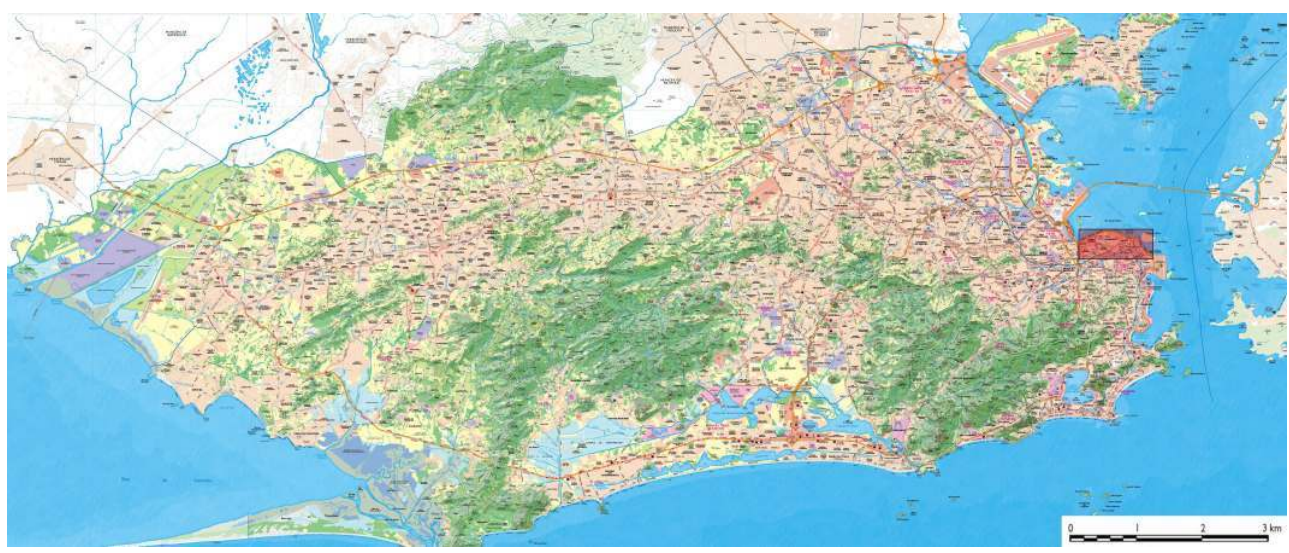

Source : armazemdedados.com.br

Figure 2. En rouge, les limites administratives du programme de revitalisation urbaine Porto Maravilha. En pointillés bleu : l'Avenida Presidente Vargas. En jaune : le Sambodrome.

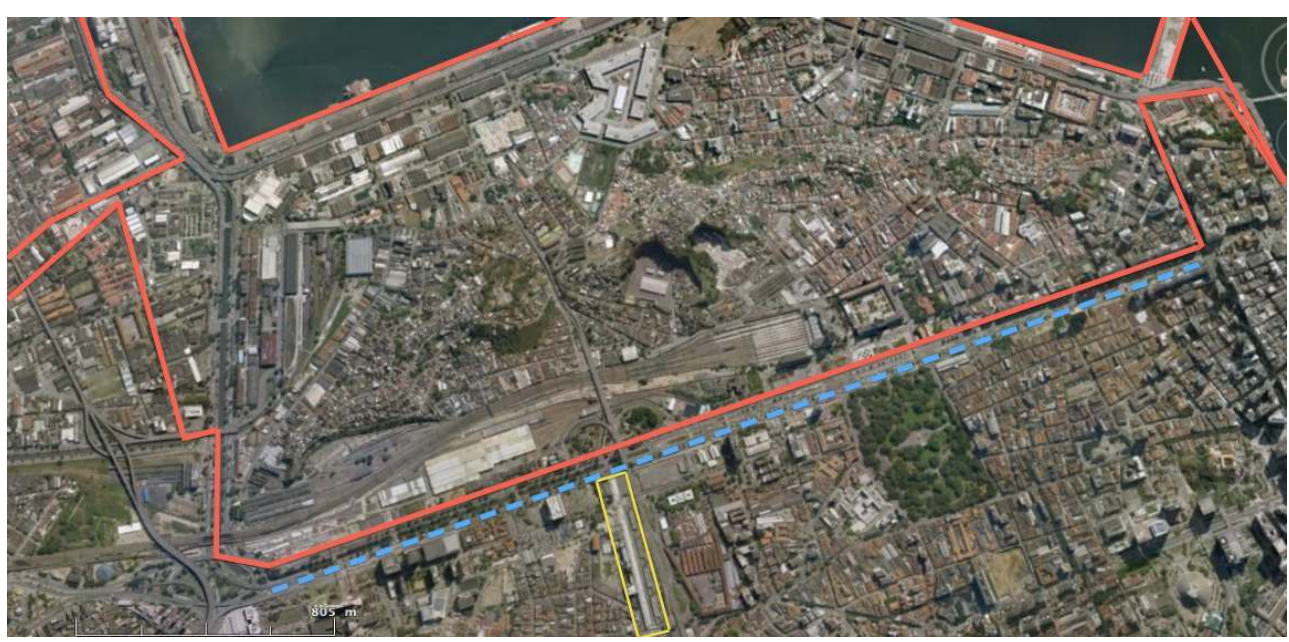

Source : Google Earth, 2013

3 La nouvelle assignation sportive à ce site emblématique de la «Ville de la Samba » fut l'occasion de réaliser des travaux de «revitalisation» du Sambodrome consistant en 
l'ouverture de nouvelles loges VIP, en un rafraîchissement des peintures des gradins et de la piste, et surtout en la construction de quatre blocs de gradins supplémentaires augmentant ainsi la jauge de 60000 à 72500 personnes. C'était ainsi qu'Oscar Niemeyer avait projeté le Sambodrome en 1984 : une avenue symétrique, culminant en une «Place de l'Apothéose » surmontée d'une sculpture gigantesque. Mais lorsque l'emplacement choisi pour sa construction s'arrêta sur l'Avenida Marquês de Sapucaí, la symétrie s'avéra impossible: la présence des usines de la brasserie Brahma, inscrites au patrimoine architectural de l'Etat de Rio de Janeiro, empêchèrent la construction de quatre blocs de gradins de l'aile ouest de l'équipement. Pendant vingt-huit ans donc, l'architecture du Sambodrome n'était pas entièrement conforme au projet d'Oscar Niemeyer.

Figure 3. Croquis du Sambodrome par Oscar Niemeyer.

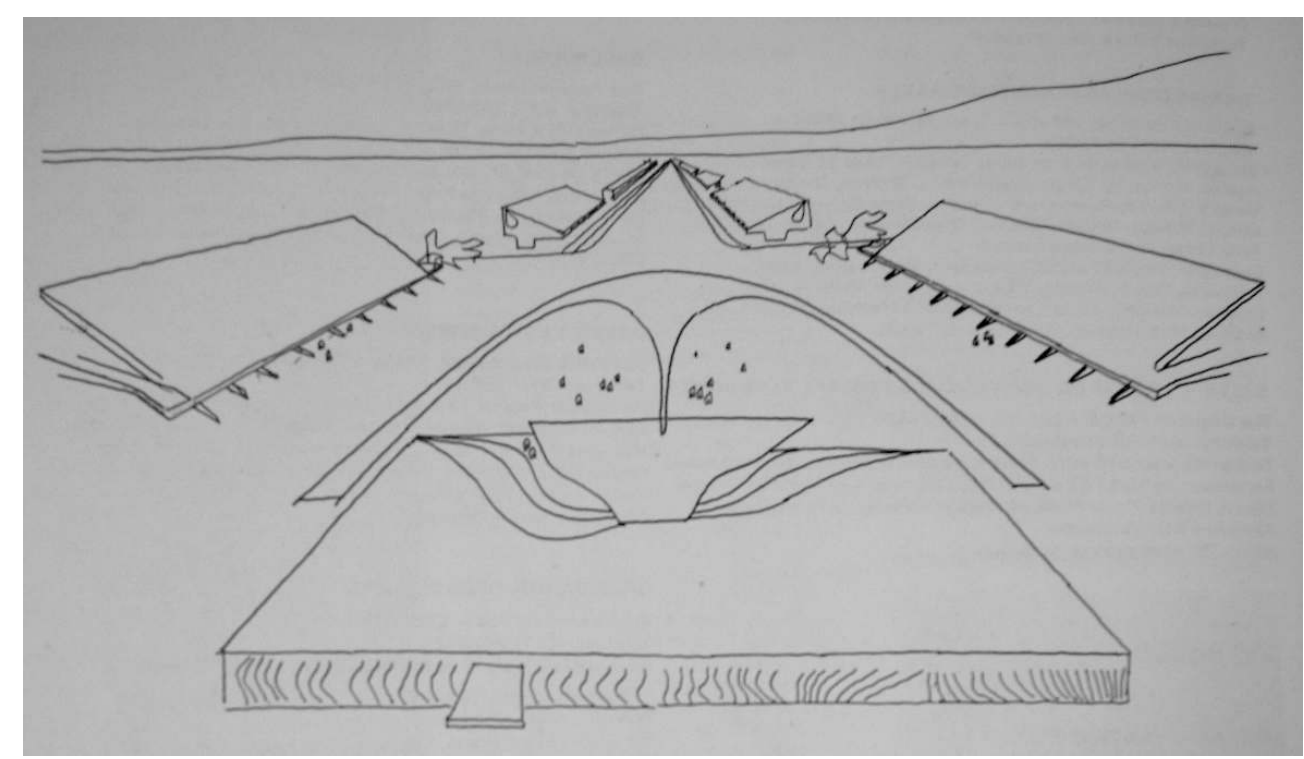

Source : Niemeyer et Susseking, 1983, 18

Il aura suffi que Rio de Janeiro gagne la course aux Jeux Olympiques pour que ce bâtiment soit déclassé des listes patrimoniales de l'État, puis détruit pour laisser la place libre aux gradins manquants. Le 8 février 2012, le « Nouveau Sambodrome » était ainsi inauguré en présence du Maire de Rio Eduardo Paes, du président du Comité Olympique Brésilien Arthur Nuzmann ainsi que d'Oscar Niemeyer, en une cérémonie œcuménique rassemblant des prêtres de l'archevêché de Rio de Janeiro et de 680 femmes de l' « aile des bahianaises $\rrbracket^{2}$ de plusieurs écoles de samba venues réaliser les rituels de purification ( $a$ lavagem) du nouvel espace, au son de l'école de samba Unidos da Tijuca. Après la récitation publique d'un « Notre Père ", le coup d'envoi d'un marathon de 5,5 km réunissant près de mille participants fut lancé depuis la « Place de l'Apothéose ». 
Figure 4. À gauche l'implosion des usines Brahma le 5 juin 2011 en présence du prefeito (ie le maire) de Rio de Janeiro Eduardo Paes. Au premier plan, le boîtier de commande décoré du logo du Novo Sambódromo. À droite, l'inauguration du Nouveau Sambodrome le 8 février 2012 en présence d'Oscar Niemeyer, de sa femme Vera et d'Eduardo Paes.

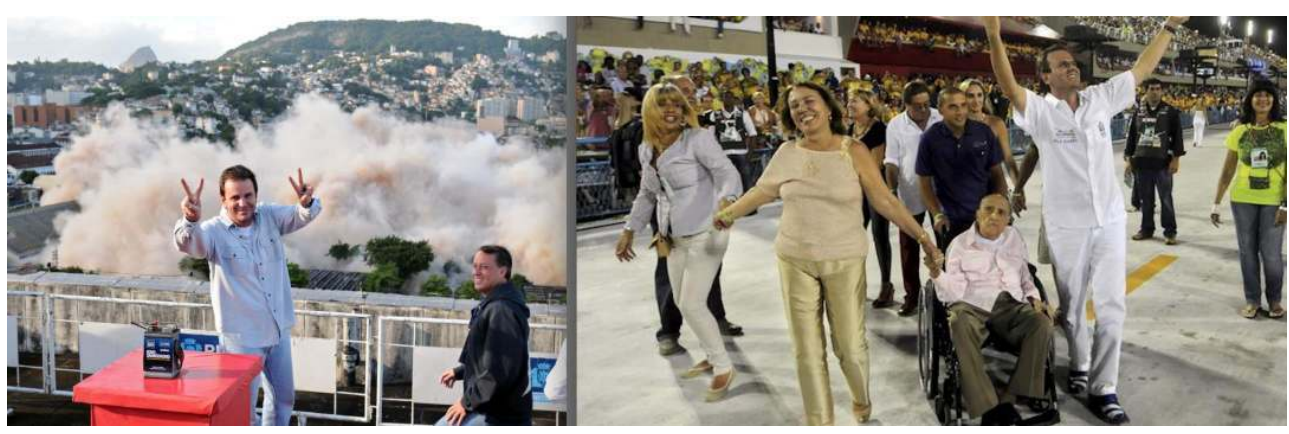

Source des deux illustrations : rio.rj.gov.br.

L'édification d'un nouvel équipement ou l'implosion d'un bâtiment historique sont souvent des événements qui diffractent les multiples représentations associées à ces lieux dont on ne parle pas tant que rien de vient bousculer leur immobilité (Werner et al., 2008). Ainsi, le chantier du « Nouveau Sambodrome ", débuté en mai 2011 avec l'implosion des usines Brahma et abouti à la veille du carnaval de février 2012, a fait affleurer parmi des habitants du quartier de la Praça Onze, et dans plusieurs médias audiovisuels militants ${ }^{3}$ des revendications concernant l'intégration de ce temple du «plus grand spectacle du monde » dans son quartier d'implantation. Quant aux premiers usagers du Sambodrome, la communauté des sambistas de Rio, sa désormais double assignation sportive et spectaculaire a donné lieu à divers récits nous renseignant sur les représentations contemporaines associées au carnaval des écoles de samba, et à son inscription dans l'espace urbain carioca.

6 S'intéresser à l'implantation du Sambodrome dans la topographie culturelle de la ville et dans la vie quotidienne de son quartier environnant est indissociable d'une réflexion sur l'expression pour laquelle il a été construit, c'est à dire sur le carnaval en tant que pratique urbaine, "produit de la sociabilité des quartiers» (Agier, 2000, p. 59). Le carnaval des écoles de samba est-il encore le lieu d'une poétique de la ville pour reprendre l'expression de Pierre Sansot (Sansot, 2004) ? Est-il encore l'espace rituel d'une invention et même d'une revendication identitaire (Agier, 2000, p. 207) ? Peut-il d'ailleurs encore être considéré comme un rituel? Commençons par explorer cette question à partir du point de vue des narrateurs en chef des défilés des écoles de samba: les

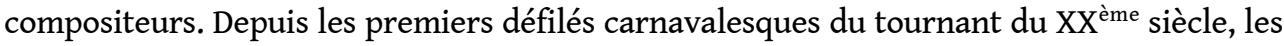
chansons populaires ont toujours été des formes de récits urbains racontant Rio de Janeiro dans ses aspects culturels, sociaux, historiques, politiques et même géomorphologiques ${ }^{4}$. La ville est pavée de chansons, de sambas notamment, qui la décrivent dans ses moindres recoins. Les chansons entonnées par les milliers de personnes qui défilent sur la piste du Sambodrome composent-elles encore Rio de Janeiro?

\section{« Ce n'est qu'une chanson »}

Lundi 25 juillet 2011, 20h. Une dizaine de personnes sont rassemblées autour d'un feu timide devant la porte d'un conteneur de chantier dont la tôle vrombit à chaque 
bourrasque. Elles sont fréquentes, en hiver, aux abords de la Ilha do Governador, cette corniche de «la Ville Merveilleuse », dans l'oeil de la Baie de Guanabara. En attendant la fin des travaux de modernisation de leur quadra, le lieu de rencontres festives et de répétition d'une école de samba, le carnavalesco Alex de Souza, directeur artistique du spectacle carnavalesque de l'école União da Ilha, donne ses rendez-vous dans ce conteneur métallique. Ce soir-là, il reçoit les compositeurs qui se sont inscrits au concours de la samba-enredo ${ }^{5}$ du carnaval 2012, c'est à dire le chant qui accompagnera le défilé de la União da Ilha lors de la compétition annuelle des écoles de samba de Rio. Au fil de huit soirées éliminatoires organisées entre la mi-août et la mi-octobre, un jury composé de spécialistes de la samba et du carnaval réduiront la liste de la trentaine de chansons inscrites au concours jusqu'à n'en garder qu'une seule, celle qui sera entonnée en boucle pendant une heure trente environ par les quelques 3000 à 4000 personnes formant le défilé de chaque école concurrente. Les Jours Gras du carnaval sont pour les écoles du Grupo Especial ${ }^{6}$ le moment où le spectacle qu'ils ont conçu pendant l'année prend vie, une vie aussi exubérante que furtive. Quatre-vingt-deux minutes de défilé au maximum, sept cents mètres à parcourir sans encombre, entre cinq et huit chars allégoriques pesant parfois plusieurs tonnes, plus de soixante-dix mille spectateurs, et cinquante experts qui vont évaluer le spectacle, puis octroyer à une unique école de samba le titre de championne de l'année. Parmi les critères très précis de l'évaluation, la samba-enredo peut être un élément décisif : depuis le premier concours carnavalesque financé par la Préfecture de Rio en 1936, de nombreuses écoles de samba cariocas sont entrées dans l'histoire de la musique populaire brésilienne grâce à la puissance d'une mélodie, la délicatesse d'une rime ou l'originalité d'une thématique. Dans l'histoire du carnaval des écoles de samba, le chant a souvent été l'écho par lequel cette éphéméride perdurait dans les mémoires ${ }^{7}$.

Cette année-là, Alex de Souza veut reproduire dans le Sambodrome une cérémonie d'ouverture des Jeux Olympiques qui mettrait en scène la passation de la flamme olympique depuis Londres en 2012 jusqu'à Rio de Janeiro en 2016. Le scénario du défilé 2012 (l'enredo) de la União da Ilha consisterait ainsi en une tentative de réunion symbolique des cultures londonienne et carioca au travers de l'expérience commune des deux villes-hôtes. Il a souhaité s'entretenir avec les compositeurs candidats pour les guider dans l'écriture des paroles destinées à être chantées quelques mois plus tard sur l' Avenida. Eduardo Paes, le prefeito (ie le maire) de Rio de Janeiro avait annoncé pendant la semaine du carnaval 2011 que pour le carnaval de février 2012, année des Jeux de Londres et de l'inauguration du "Nouveau Sambodrome", la Préfecture soutiendrait financièrement l'école de samba qui choisirait de consacrer son enredo aux Jeux Olympiques. La União da Itha avait alors informé la presse dans les premiers jours du mois de mars 2011, soit quelques jours après la clôture du carnaval, de ses intentions d'inviter dans son prochain défilé ce sujet qui déjà en 2011, comptait parmi les plus brûlants de l'actualité carioca. Mais cette déclaration n'a pas eu bonne presse, les premières « levées de bouclier " ont été faites dans la semaine du 12 mars 2011, principalement sur les réseaux sociaux (notamment facebook et twitter) et dans les commentaires d'internautes des journaux locaux en ligne. Ses détracteurs reprochaient à Alex de Souza de rompre avec la tradition des sambas-enredo qui ont fait, par le passé, le succès de la União da Ilha. Pour certains d'entre eux, la référence aux Jeux Olympiques de 2016 était un "appât » financier de la Préfecture de Rio auquel la União da Ilha n'avait pas su résister. 
9 Un peu plus tard dans la soirée, je profite d'une pause pour échanger quelques mots avec l'un des candidats du groupe de compositeurs (la parceria) qui vient de présenter sa samba-enredo inachevée: Aloisio, 32 ans et déjà treize ans d'expérience en tant que parolier de sambas-enredo a fait très bonne impression auprès d'Alex de Souza. Ce dernier a jugé ses paroles " très délicates » et " conformes au synopsis ». Je ne le sais pas encore, mais la parceria d'Aloisio sera justement la finaliste du concours de la samba-enredo 2012, l'auteur du chant qui retentira sur la piste du Sambodrome en février 2012. Je tente de le questionner sur son opinion à propos des projets de renouvellement urbains menés sur les futurs territoires olympiques de Rio, et sur l'acte de chanter les louanges des Jeux Olympiques sur l'Avenida des écoles de samba. Sa réponse est ferme: pour lui, la polémique accompagnant le choix de la thématique du prochain défilé de la União da Ilha est un faux débat. Une samba-enredo n'a jamais eu pour but d'être un miroir de la société ou de «de la vraie vie » m'explique-t-il ; «ce n'est qu'une chanson». Le carnaval des écoles de samba n'est pas non plus le lieu où la ville se raconte: "c'est comme un immense conte de fée et les milliers de personnes qui participent au carnaval, elles sortent de leur quotidien, il est fait pour être heureux en oubliant tous ses problèmes, on parle de la magie du carnaval ». Quant au Sambodrome, il n'a jamais été voué à être un lieu d'écho aux questions sociales, politiques ou culturelles brésiliennes d'actualité : « ça, c'est le rôle de l'autre carnaval, celui de la rue, pas celui des artistes des écoles de samba ». Aloisio fait ici référence au carnaval de rue dont les groupes musicaux et festifs ne sont pas incarnés par les écoles de samba mais par des blocos, des groupes de percussions ou des fanfares liées à un quartier particulier de la ville, et pouvant rassembler jusqu'à deux millions de personnes pour les plus connus d'entre eux. Depuis quelques années, se créent de plus en plus de blocos " engagés ", c'est-à-dire militant pour la préservation d'un carnaval de rue traditionnel, indépendant des services de tourisme de la ville, et remettant à l'honneur les chants satiriques sur les personnalités politiques et les faits d'actualités.

10 C'est pourtant depuis le Sambodrome que nous parviennent, en France comme dans plus d'une centaine d'autres pays, les images les plus impressionnantes des reportages de presse sur le Carnaval de Rio : des images de danseuses plantureuses, légèrement vêtues de roues de plumes accrochées dans le dos et rivalisant d'aisance dans la samba no pé; des costumes hallucinants de couleurs et de sophistication, des chars motorisés surplombés de décors aux dimensions démesurées ; ce sont aussi des bruits sourds de foule en liesse, des feux d'artifice, et bien sûr plusieurs centaines de percussionnistes jouant comme un seul les rythmes syncopés de la samba-enredo de leur école de cœur. Ces images du carnaval des écoles de samba se fondent souvent, dans nos flashes infos outre-atlantique, avec celles de l'autre carnaval, non pas celui, « officiel», du «plus grand spectacle du monde », mais celui « des rues ». La scène d'évolution de ce carnaval de rue n'est pas un équipement affecté au carnaval mais l'espace public urbain lui-même. Finalement, Aloisio conclut sans hésitation: ce qui est annoncé tous les ans comme «le carnaval officiel de Rio de Janeiro ", c'est-à-dire le défilé des écoles de samba, n'a plus rien d'un carnaval. Quant au Sambodrome, s'il apparaît encore dans les plans de la ville comme la Avenida Marquês de Sapucai, là aussi, il ne lui reste plus de l'avenue que le nom : ses trottoirs sont des gradins pouvant accueillir désormais jusqu'à 76500 personnes et elle n'est pas ouverte à la circulation. Une semaine par an, les dizaines de chars et les milliers de danseurs de chaque école de samba en font leur piste de répétition, de représentation et de parade de clôture, mais le reste de l'année l'Avenida a les allures de stade abandonné. 
Figure 5. À gauche, l'Avenida Marquês de Sapucaí, le Sambodrome, pendant le carnaval des écoles de samba. À droite, l'Avenida Marquês de Sapucaí, le 22 novembre 2010.

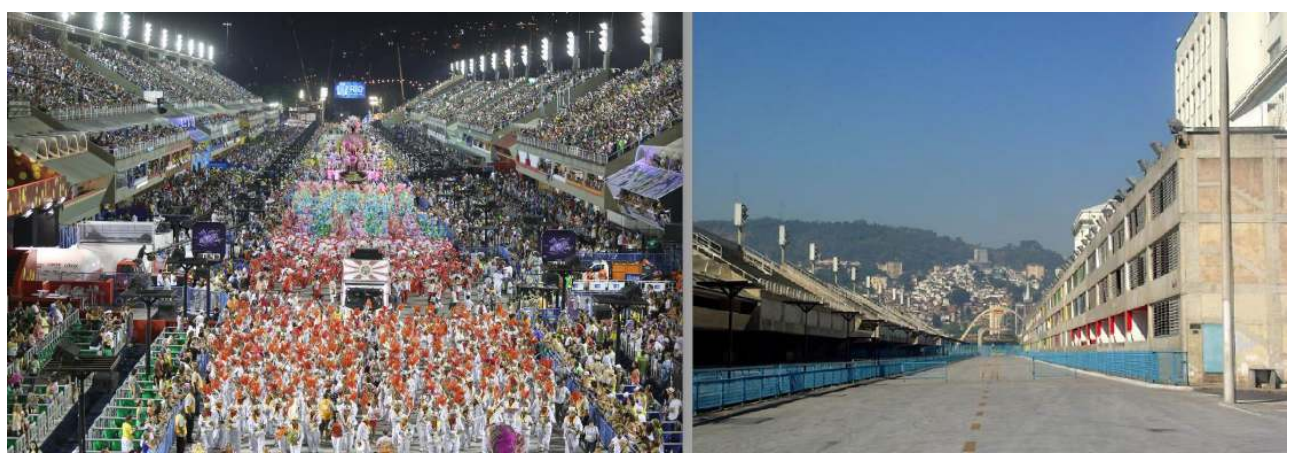

Crédits photo de gauche: Riotur ; Crédits photo de droite : André Mendonça

Si l'on en croit la bibliographie consacrée, les origines historiques de ce spectaclecompétition communément datées au début $\mathrm{du} \mathrm{XX}^{\text {ème }}$ siècle avaient tout de cette «liminarité permissive» dont parle Michel Agier à propos des carnavals populaires (Agier, 2000, p. 229) : les premiers défilés carnavalesque qui au tournant des années 1930, auraient donné naissance aux premières écoles de samba, consistaient en de véritables « prises en scène » de la ville par la population afro-brésilienne marginalisée du port. Non autorisés par la Préfecture (ie la mairie) de Rio jusqu'en 1936, ce « Petit Carnaval » était ignoré des médias locaux et nationaux qui ne portaient en estime que le "Grand Carnaval », celui des quartiers bourgeois de la ville, inspiré des carnavals européens. Avant qu'ils ne deviennent «le plus grand spectacle du monde », les défilés des écoles de samba étaient donc une pratique de revendication de la communauté des esclaves et de leurs descendants récemment libérés (1888), l'expression de leur droit à exister dans Rio, la capitale d'alors qui cherchait à s'imposer comme vitrine moderne du Brésil (Costa, 2001 ; Pereira de Queiroz, 1992). Parmi les actes visant à normaliser le défilé compétitif des écoles de samba, le plus fondateur est sans aucun doute la réglementation de 1935, qui a fait de cette manifestation populaire un événement officiellement organisé par la Préfecture de Rio de Janeiro (Vianna, 1995). Mais lorsqu'en juillet 1983, le gouverneur de l'Etat de Rio de Janeiro de l'époque, Leonel Brizola, a signé la construction d'un lieu permanent spécifiquement dédié au défilé des écoles de samba, le décrochage déjà à l'oeuvre entre le "plus grand spectacle du monde ", et la participation du "peuple " carioca a été consolidé. La tentation serait donc grande de faire du Sambodrome le hautlieu inversé de ce passé déchu, d'expliquer par sa construction la spectacularisation des œuvres carnavalesques des écoles de samba de Rio. Mais ce serait faire erreur. Le Sambodrome n'a pas à lui seul opéré le renversement que l'on peut lire dans la transformation du «Petit Carnaval» du début du siècle, un mode de déambulation transgressant le cadre topographique et médiatique du « Grand Carnaval » officiel, en un défilé spectaculaire affecté à un lieu fixe et aujourd'hui intitulé «Carnaval officiel de Rio de Janeiro ». Il n'est pas non plus la cause de la déflation symbolique, de la perte de spontanéité et de la mise en place d'une politique tarifaire excluant les plus pauvres que récusent les nostalgiques du carnaval historique (Cavalcanti, 1999). Bref, le Sambodrome n'est pas le moteur de la transformation du défilé des écoles de samba, il en est l'estampille, le symbole de ce que le carnaval des écoles de samba ne sera jamais plus à Rio de Janeiro : un rituel populaire marqué par le retournement, une "fête à l'envers " comme le dit Daniel Fabre pendant laquelle les espaces géo-sociaux de la ville et les rôles 
sociaux s'inversent ${ }^{10}$. Loin d'être le lieu responsable de la spectacularisation du carnaval certains parlent même de " muséification » (Chagas, 2002, pp. 15-18) - cette fausse avenue qui compte parmi les icônes architecturaux les plus présents sur la scène médiatique internationale est en réalité l'équipement scénique grâce auquel le défilé annuel des écoles de samba a pu se maintenir dans la ville.

12 Aujourd'hui, les origines transgressives ${ }^{11}$ du carnaval des écoles de samba sont davantage un objet de nostalgie qu'un vestige historique que l'on pourrait encore déchiffrer dans les défilés contemporains. Nombreux sont les sambistas ou les grands amateurs de samba et de carnaval qui regrettent le temps où le carnaval des écoles de samba et leurs sambaenredos n'étaient pas aussi formatés qu'ils ne le sont aujourd'hui. « Avant, quand les écoles de samba défilaient dans la rue... », «avant, quand le carnaval de Rio n'était pas juste un spectacle pour touristes", "avant, quand le carnaval des écoles de samba était encore celui peuple ", " avant la professionnalisation du carnaval » etc. Évoquer sa saudade de la samba des racines (samba de raiz) et du carnaval du passé est non seulement une posture consacrée de la vieille-garde des écoles de samba (a velha guarda), mais aussi un répertoire chansonnier à part entière. Les sambas dont les paroles regrettent un âge d'or mythique des origines sont innombrables. Et ces origines sont assez largement placées au début du $\mathrm{XX}^{\mathrm{ème}}$ siècle, dans le centre historique de la ville, entre la Praça Onze où a été construit le Sambodrome et la bordure du port. Autrement dit, l'espace urbain mythique des origines de la samba et du carnaval trouvent leur premier lieu de mémoire dans le répertoire des chansons composées tout au long du $\mathrm{XX}^{\text {ème }}$ siècle par des générations de musiciens à propos de la transformation de leur ville, de leurs quartiers, de leur musique. Les sambistas de la première moitié $\mathrm{du} \mathrm{XX}^{\text {ème }}$ siècle, attachés à raconter une Rio de Janeiro qui jurait avec la «Ville Merveilleuse » que l'on voulait fabriquer comme la métonymie d'un Brésil moderne, hédoniste et exotique ne trouveraient donc plus dans le défilé des écoles de samba un espace approprié aux chroniqueurs urbains qu'ils étaient alors. C'est en revanche dans l'espace d'accueil de ces défilés, dans ce Sambodrome construit exclusivement pour eux, qu'ils trouveraient la marque de reconnaissance et de valorisation permanente de la culture populaire carioca que les premières déambulations du Petit Carnaval du tournant du XXème siècle entendaient obtenir. Le Sambodrome a été une des conditions à ce que le carnaval de Rio demeure un des emblèmes de la ville, et du Brésil. Cette adoption du carnaval des écoles de samba comme icône de la culture brésilienne fut pour beaucoup une acmé à double tranchant, et continue de l'être, à l'heure où de plus en plus de voix s'élèvent contre la primauté de la politique mégaévénementielle de Rio de Janeiro dirigée vers le tourisme international au détriment de programmes de développement social et éducatif destinés aux populations les plus marginalisées de la ville. Le Sambodrome projeté en 1984 par l'architecte Oscar Niemeyer, le gouverneur de l'État de Rio de Janeiro et son vice-gouverneur, devait pourtant être le lieu d'une politique intégrée qui aurait fait se côtoyer dans le même espace les plus riches et les plus pauvres, les spectacles les plus grandioses et éphémères et les programmes de développement culturel, éducatif et social les plus durables. Faisons quelques pas en arrière, trente ans exactement, pour se figurer ce fameux Sambodrome de Rio de Janeiro lorsqu'il n'était encore qu'à l'état de projet. 


\section{L'utopie du Sambodrome}

13 La décision d'offrir au carnaval de Rio un territoire qui lui serait exclusivement attribué était un projet que la majorité des sambistas appelaient de leurs vœux, et qui était régulièrement annoncé dans les programmes de développement urbain et économique de l'État de Rio de Janeiro. Après avoir déambulé entre 1936 et 1942 dans les rues situées autour de la principale place publique du centre historique (la Praça Onze, aujourd'hui détruite), puis le long de l'Avenida Presidente Vargas, les douze meilleures écoles de samba de la ville défilèrent à partir de 1978 sur l'Avenida Marquês de Sapucai, l'une des artères principales de circulation du centre historique de la ville, à l'entrée de sa zone portuaire. Le montage et le démontage des tréteaux supportant les gradins, les passerelles et les lieux de passage du public (bars, billetteries, toilettes publiques) se faisaient chaque année plus lourds et plus coûteux, bloquaient toujours plus longtemps la circulation automobile dans les rues adjacentes et créaient des embouteillages qui se répercutaient dans toute la ville. En 1983, la mise sur pied des gradins de cet équipement amovible s'étalait sur plus de huit mois du calendrier annuel (Moura, 1986, p. 80) tandis que le préfet municipal d'alors, Jamil Haddad, déclara ne plus disposer des fonds publics nécessaires pour que le carnaval des écoles de samba continue à avoir lieu sous ces conditions. Après de multiples débats, le gouverneur de l'État de Rio de Janeiro de l'époque, Leonel Brizola, annonça sa décision de construire un équipement définitif et permanent pour le carnaval. Le choix d'implantation qu'il formula pour ce projet architectural était celui du territoire historique du carnaval de Rio, là où au début du XX ème siècle se seraient formés les premiers groupes carnavalesques: non pas ceux de la bourgeoisie locale qui s'inspiraient des carnavals européens et défilaient près du bord de mer dans des ranchos sophistiqués, les Grandes Sociedades, mais ceux de « la Petite Afrique de Rio $»^{12}$. Cet équipement permanent devait pouvoir accueillir au moins soixante mille spectateurs, prioritairement cariocas, et impliquer un coût unique global qui n'excèderait pas le double de celui dépensé annuellement pour la mise en place et le démontage des gradins amovibles.

Leonel Brizola venait de nommer comme vice-gouverneur de l'État de Rio de Janeiro l'anthropologue, éducateur et politicien Darcy Ribeiro. Ce dernier avait pour principale mission d'opérer une " véritable révolution éducative dans le pays ", en faisant construire dans les territoires défavorisés des grands centres urbains brésiliens un réseau de "Centres Intégrés d'Enseignement Public ». Ces centres, véritables icônes de la carrière politique de Darcy Ribeiro, étaient des écoles fonctionnant à temps complet, pouvant accueillir jusqu'à 1000 élèves en leur offrant l'enseignement scolaire en vigueur ainsi que des activités culturelles et un accompagnement médical. L'architecte mandaté pour la réalisation de ces nouveaux équipements éducatifs n'était autre qu'Oscar Niemeyer. C'est à lui également que fut confiée la conceptualisation du projet architectonique de la Passerelle de la Samba, et à l'ingénieur Jorge Carlos Sussekind le soin de le réaliser en bonne et due forme. Le trio Brizola-Ribeiro-Niemeyer annonça donc à la presse le 11 septembre 1983 que le prochain carnaval aurait lieu dans un équipement permanent destiné exclusivement aux écoles de samba pendant les Jours Gras, et le reste de l'année, en journée, aux seize mille élèves de "Centres Intégrés d'Enseignement Public » qui seraient construits sous les gradins de ciment. Le soir, la Praça da Apoteose clôturant la Avenida se transformerait en salle de bal à ciel ouvert pouvant accueillir jusqu'à vingt 
mille couples. Fidèle à ses engagements visionnaires pour l'éducation et le respect des droits des populations les plus défavorisées (Ribeiro, 1968), Darcy Ribeiro avait conçu ce Complexo da Avenida dos Desfiles, comme il l'était initialement nommé, comme un projet visant à inverser la stratification sociale du public des écoles de samba, déjà à l'oeuvre depuis les années 1960.

"L'idée principale du projet, son innovation majeure, c'est l'importance accordée à la participation populaire, qui a été exclue des défilés, et qui n'avait accès au carnaval que moyennant des sommes absurdes. Désormais, toute la population pauvre aura la possibilité d'assister au carnaval. Oscar a dessiné un projet très bien conçu, dans lequel les gradins surélevés pourront laisser un espace libre en-dessous pour une foule relativement importante, qui pourra donc voir gratuitement les défilés $»^{13}$.

Le but affiché était ainsi de rendre le carnaval des écoles de samba aux franges de la population carioca qui l'avaient vu et fait naître. Ce carnaval historique, populaire, né dans les quartiers de la zone du port industriel au tournant du XX ${ }^{\text {ème }}$ siècle (Pereira de Queiroz, 1992) s'était forgé comme un pied de nez lancé à l'autre carnaval, celui des grandes sociétés musicales des quartiers aisés de la capitale brésilienne d'alors, qui évoluaient "plus calmement" aux rythmes des scottishs, polkas et airs d'opéra européens en vogue. C'est ce "Petit Carnaval» d'une Rio ouvrière, majoritairement bahianaise (Moura, 1983), traversé de multiples et diverses références à la culture et aux religions afro-brésiliennes, qui dans les années 1920 donna naissance à la première école de samba de Rio de Janeiro. Le rêve proclamé par le trio Brizola-Ribeiro-Niemeyer était ainsi celui d' « espace social total » (Trajano, 1999). D'une part, le Sambodrome devait être un monument-hommage à la manifestation culturelle qui déjà en 1983, représentait la principale source de rayonnement de Rio de Janeiro sur la scène internationale. D'autre part, le Sambodrome devait relever le défi d'une réintégration de l'espace du carnaval des écoles de samba dans la symbolique et la réalité sociale, culturelle et morphologique de son territoire d'origine.

En l'espace de cent dix jours, l'Avenida Marquês de Sapucai quitta son statut d'avenue pour endosser celui d'espace scénique permanent composé d'une piste de sept cents mètres de long bordée de gradins et clôturée par une place circulaire. Avec le Sambodrome, Rio de Janeiro a érigé un modèle d'intégration urbaine d'une manifestation populaire que nulle autre "ville carnavalesque» n'avait encore jamais ébauché. Pendant la décennie suivante, d'autres projets architecturaux similaires ont exporté l'oeuvre niemeyrienne au-delà des frontières de l'État fluminense ${ }^{14}$ : Manaus (1986), Florianopolis (1989), São Paulo (1991), Porto Alegre (2003) ont construit leurs propres Sambodromes en ne gardant du projet originel que son rôle d'équipement dédié au carnaval des écoles de samba, sans le volet social et culturel projeté par Darcy Ribeiro. Les projets éducatifs et sociaux que devaient occuper le Sambodrome pour les habitants de son quartier d'implantation en dehors des jours de carnaval n'auront jamais pris forme, ni à Rio de Janeiro ni ailleurs au Brésil. En effet, ce Complexo da Avenida dos Desfiles pouvant changer de visage à la demande, de la scène du " plus grand show de la planète » jusqu'au parquet de bal, en passant par la cour de récréation commune pour une quinzaine d'écoles aux pédagogies progressistes, ce Sambodrome-là entrera dans l'histoire sociale et urbaine de Rio de Janeiro comme une des plus grandes utopies urbaines du Brésil, dont le destin aura pris une tournure nettement antinomique à celle qui lui était prédite. Dès le carnaval de février 1984, le projet populiste proclamé n'avait aucune chance de se réaliser, eu égard aux prix extrêmement élevés des tickets d'entrée ${ }^{15}$, et à l'abandon du projet initial de 
surélévation des gradins laissant un espace libre au niveau de la rue, de façon à ce que les défilés soient visibles gratuitement pour un public à faible revenu. Dans une lettre adressée au gouverneur de l'État de Rio de Janeiro, Oscar Niemeyer déplore que les principes qui avaient présidé à la conception de sa Passarela do Samba n'aient pas été respectés :

«Pour moi le succès du Sambodrome n'est pas dans la vente des billets ni dans les retombées économiques qu'il peut offrir, mais dans l'intégration du Peuple au sein de ce spectacle qui a toujours été le sien, et dont il devrait pouvoir profiter pour un prix modique. Mon idée était de le placer sous les gradins pour que, debout, il puisse participer aux défilés comme avant. Le retirer de cet espace, maintenant complètement rempli de tables et de bars ambulants, c'est l'oublier totalement, et c'est donner au Sambodrome un caractère discriminatoire, le destiner à divertir la bourgeoisie exhibitionniste qui va venir applaudir ses frères les plus pauvres et les oublier le jour d'après, comme cela a toujours été le cas. $»^{16}$

Quant à l'espace qui devait être dévolu aux écoles municipales à temps complet, le Sambodrome en aura certes abrité entre 1985 et aujourd'hui, mais loin des seize mille élèves annoncés, les quelques coulisses effectivement aménagés en salle de classe ne verront rarement plus de mille cinq cents enfants inscrits annuellement.

\section{Le Sambodrome insulaire}

En 2010, les écoles n'occupaient plus que deux secteurs sur treize du Sambodrome, pour moins de sept cents élèves inscrits ${ }^{17}$. Et au tournant de l'année 2011, avant que les travaux $\mathrm{du}$ « Nouveau Sambodrome » ne commencent, les parents de six cents soixante-dix élèves des CIEPS da Avenida dos Desfiles recevaient l'annonce de la fermeture des classes et du transfert obligatoire des enfants dans des écoles municipales de la région. Cette décision très peu relayée par les médias locaux a pourtant eu de lourdes conséquences pour des centaines de familles des quartiers de la zone Centre. Je rencontrai l'une d'entre elle peu après le carnaval de 2011: Juliana, 27 ans et mère de deux enfants inscrits à temps complet (8h-17h) dans une des classes du Sambodrome, habitant dans une zone favelisée du quartier voisin de Catumbi. La fermeture des CIEPS de l'Avenida dos Desfiles l'obligeait à arrêter de travailler, puisque chacun de ses deux enfants serait transféré dès la semaine suivante dans deux écoles différentes de la région, à temps partiel (8h-midi), et distantes de près de deux kilomètres l'une de l'autre. Ne disposant d'aucun moyen de transport privé, et sa communauté étant très mal desservie en transports publics, elle se voyait obligée de poser sa démission. Interrogé par un journaliste du journal «Extra » à propos de cette décision, le chef de cabinet du Secrétariat Municipal à l'Éducation déclarait que le Sambodrome n'était plus un lieu d'éducation adéquat pour les programmes scolaires municipaux puisque la période de répétitions, de défilés et de démontages des chars des écoles de samba s'allongeaient d'année en année et obligeaient les écoles municipales installées dans le Sambodrome à écourter leur calendrier d'enseignements ${ }^{18}$. Cet argument qui n'avait jamais été avancé avant l'année 2011 camouflait assez malhabilement les effets collatéraux d'un programme de « revitalisation du Sambodrome » qui allait subrepticement révéler l'existence de ce qui a toujours été le grand absent des polémiques associée à l'Avenida depuis sa construction: c'est à dire son territoire d'implantation. Les écrits journalistiques et scientifiques consacrés au Sambodrome et aux vives polémiques qui ont accompagné les cent dix jours de sa construction sont légions dans la bibliographie brésilienne dédiée au carnaval des écoles de samba. En 
revanche, très peu d'enquêtes ont été menées sur la façon dont cet équipement s'est intégré à l'espace urbain local, sa vie sociale, économique et culturelle ${ }^{19}$.

Nommer la ville en revers de l'Avenida pose un premier problème d'ordre sémantique : nul ne s'accorde sur le nom à donner au quartier environnant. Administrativement, l' Avenida Marquês de Sapucai se trouve à l'exacte frontière séparant les quartiers administratifs de la Cidade Nova et du Centro. Pourtant, les documents de communication édités par les services touristiques de la Préfecture de Rio et destinés aux spectateurs du défilé des écoles de samba parlent du quartier de la Praça Onze, du nom de la station de métro la plus proche. Les habitants des rues entourant l'extrémité Nord du Sambodrome parlent pour la plupart du quartier du Balança, reprenant le nom officieux donné à un complexe immobilier de trois immeubles de vingt-et-un étages situé à deux cents mètres à l'est de l'Avenida. Ceux de l'extrémité Sud se disent habitants du quartier de la sousrégion administrative de Catumbi. Lorsque j'interrogeai ces habitants sur le nom qu'ils donnaient au territoire délimité à l'ouest par la station de métro «Praça Onze », à l'est par le Sambodrome et au nord par l'Avenida Presidente Vargas, ils m'indiquaient pour plus des trois quart d'entre eux qu'il s'agissait du sous-quartier de la Praça Onze faisant partie du district administratif de la Cidade Nova. Les projets monographiques qui viseraient à enquêter sur le quartier d'implantation du Sambodrome ne peuvent donc qu'être brimés par l'hétérogénéité de ses formes d'identification, qu'elles soient énoncées par des opérateurs culturels locaux, des habitants, des responsables d'instances politiques publiques, ou des usagers d'établissements voisins ${ }^{20}$. Dans tous les cas, «le quartier du Sambodrome » est une dénomination qui ne fonctionne que pour ceux qui n'y habitent pas : si ce monument du carnaval carioca tient lieu de référence à l'échelle du plan de la ville, ce n'en est pas systématiquement une pour les habitants de ses rues environnantes. Il est d'ailleurs révélateur de constater que la seule toponymie faisant référence à la présence du Sambodrome dans le quartier est celle d'une favela: la «favela do Sambódromo ", dont les habitants ont été délogés (et pour certains relogés, mais à cinquante kilomètres de là) et dont les habitations ont été détruites en mai 2011, quelques semaines avant la construction du dernier bloc de gradins de l'aile ouest du Sambodrome.

L'histoire de ce quartier informel à la lisière du centre historique et de la zone portuaire est scandée de multiples expérimentations de rénovation urbaine qui, bien qu'aucune n'ait jamais été menée à terme, ont laissé de véritables cicatrices ${ }^{21}$ dans le tissu urbain. Entre 1966 et aujourd'hui, au moins six plans de réforme ont été signés et ont donné lieu à d'amples opérations de démolition du parc immobilier existant, justifiées par l'implantation d'infrastructures autoroutières surélevées, de l'ouverture de trois stations de métro ${ }^{22}$, ou de la construction du centre administratif de la Préfecture et des Archives Municipales. Ces plans de rénovation ont servi d'alibis à de nombreuses démolitions d'habitations traditionnelles vétustes (Ferreira dos Santos, 1981 et 1985), légitimées par la construction de pôles commerciaux, administratifs ou de services qui ne voyaient jamais le jour, et laissaient d'innombrables vides urbains. Le Sambodrome est ainsi né d'une abrogation d'un des principes directeurs du "Plan de Reformulation de la Cidade Nova " de 1980 qui préconisait un usage mixte (résidentiel et commercial) pour l'Avenida Marquês de Sapucai. Un vide urbain en a remplacé un autre. Ce n'est qu'en 1998 que pour la première fois dans la chronologie des projets de revitalisation coordonnés par le Secrétariat Municipal à l'Urbanisme, une série de résolutions spécifiques ont été indiquées pour un meilleur usage et une meilleure intégration du Sambodrome dans le tissu urbain local. Outre le maintien et l'intensification de l'usage social de l'équipement 
assuré par les écoles municipales, il était ainsi préconisé d'y installer des « incubateurs de carnaval » qui dispenseraient des activités musicales et plastiques à temps complet, tout au long de l'année. Enfin, il était prévu d'aménager une partie de la place de l'extrémité sud du Sambodrome en parc public destiné aux habitants des rues alentour. Cette mention du Sambodrome comme espace moteur d'une régénération du quartier administratif de la Cidade Nova sera restée à l'état de projet, et n'apparaîtra plus jusqu'en 2011 dans les plans de développement urbain portés par la Préfecture de Rio.

21 À l'heure où le territoire du Porto Maravilha est saturé de programmes valorisant la mémoire culturelle des monuments, habitations, bâtiments industriels et voiries en rénovation, derrière la limite administrative de l'Avenida Presidente Vargas, les brasseries Brahma construites à la fin du XVIII ${ }^{\text {ème }}$ siècle vivaient leur dernière heure le 5 juin 2011. Pour l'historien brésilien Milton Teixeira interrogé par le journal o Globo un mois avant l'implosion des bâtiments, la brasserie Brahma était d'une grande valeur patrimoniale en ce qu'elle cristallisait le métissage culturel qui avait donné naissance à la samba de Rio : l'industrie européenne (suisse en l'occurrence) et la culture africaine; entendons par-là : bière et percussions. Cette assertion était peu contestable, du moins pour ce qui est de la valeur patrimoniale des bâtiments, puisque depuis 1994, les anciennes usines Brahma étaient entrées au registre de l'Institut du Patrimoine Culturel de l'État de Rio de Janeiro au titre de bien de valeur historique «d'ambiance»; l'objet «noyau» de la patrimonialisation étant le Sambodrome. Il a suffi de se référer à l'article 6 du 13 juillet 1982 stipulant la possibilité d'annuler l'inscription d'un bien au registre patrimonial dès lors qu'il en va du "développement économique et social de l'État», pour que le Sambodrome quitte son statut de bien patrimonial «noyau», que les usines Brahma puissent être démolies, que le secteur manquant de l'architecture conceptualisée pas Oscar Niemeyer puisse être construit, et que la cinquantaine de familles installées dans les habitations illégales de la Favela do Sambodromo soient expulsées. Après dix ans passés sans que nul énième plan de rénovation des alentours du Sambodrome ne soit annoncé, le quartier administratif de la Cidade Nova, longeant l'aile ouest du Sambodrome, et une partie de la sous-région administrative de Catumbi, à l'extrémité sud, ont retrouvé leur éternel statut de «territoire projet». Pourtant, une semaine par an, ce quartier du Sambodrome qui peine à se stabiliser autour d'un nom, d'une identité et même d'un découpage administratif, se retrouve traversé par près de deux cents mille personnes pendant les deux nuits du Carnaval officiel de Rio de Janeiro, et sous les regards de toutes les télévisions du monde.

\section{Revitaliser la Praça Onze, berceau de la samba}

Lundi 20 février 2012, nous sommes au seuil de la seconde nuit du Carnaval officiel de Rio de Janeiro. La plupart des spectateurs et des participants au défilé ont emprunté la ligne 1 du métro et en sont sortis à la station " Praça Onze », dont les murs sont tapissés de larges affiches retraçant l'histoire du berceau de la samba et du carnaval. Autour du Sambodrome, les rues sont saturées de kiosques vendant boissons, nourriture, et costumes de fête. Au pied de l'aile est, surplombant l'entrée de la piste, se trouve le plus grand complexe résidentiel de la zone Centre de Rio, le Balança Mas Não Cai, «l'immeuble qui penche mais ne tombe pas ». En bas de ses trois tours, le trottoir déborde de tables en plastique bleues et jaunes généreusement jonchées de bouteilles vides. Des familles, des groupes d'amis de tous les âges y sont assis et parlent, crient, chantent, se lèvent, se 
rassoient dans une effervescence collective diluant tout effet de groupe : tout le monde a l'air de se connaître. Le propriétaire du bar a placé devant le comptoir une imposante enceinte diffusant les airs d'un mélange de samba, de pop et de techno. Ceux-ci se font de moins en moins audibles à mesure que l'on s'avance dans la soirée et que le bruit sourd des feux d'artifices et des batteries des écoles de samba s'échappe du Sambodrome. Certains portent des costumes particulièrement sophistiqués. Ils sont d'ailleurs assis vers l'extérieur de cette terrasse improvisée, là où il y a plus de place, tant leurs apparats sont encombrants. Dans quelques dizaines de minutes, ou quelques heures peut-être, ils devront se poster à trente mètres de là, sur l'aire de concentration des écoles de samba, à l'entrée de la piste de défilé. A la sortie du Sambodrome, après l'aire de "déconcentration", les milliers de danseurs ayant souvent acheté leurs costumes à des prix faramineux sont sommés de quitter les lieux le plus vite possible, pour ne pas créer d'embouteillages. Dans les rues adjacentes bloquées à la circulation autoroutière, un petit marché informel de costumes de mousse, polystyrène, plumes, cartons, plastiques s'organise. Beaucoup de danseurs se délestent de leurs coûteux apparats dès qu'ils quittent l'Avenida et qu'ils reviennent dans la rue. Ils les jettent alors sur le bas-côté où ils ne resteront pas bien longtemps avant d'être récupérés par toutes sortes d'intéressés.

Entre les trois tours du Balança, dans une étroite ruelle séparée de la rue par un grillage qui ne ferme pas, sept hommes d'une cinquantaine d'années jouent aux cartes. Comme tous les soirs. Seul l'un d'entre eux, un ancien compositeur de l'école de samba de Mangueira, se retourne régulièrement vers le minuscule poste de télévision perché à l'entrée de la ruelle, derrière les fenêtres d'une épicerie qui ce soir tient lieu de bar, pour jauger en un coup d'oeil la qualité des défilés retransmis en live. La bande sonore, il la reçoit en temps réel, sans intermédiaire, depuis la piste du Sambodrome cachée à la vue par les gradins. Les autres n'y prêtent guère attention. Cela fait entre dix-sept et quarante-neuf ans qu'ils habitent dans le quartier. Eux l'appellent le quartier du Balança pour dénommer leur pâté de maison, et le quartier de la Praça Onze pour parler des rues qu'ils arpentent quotidiennement lorsqu'ils sortent de chez eux pour aller travailler, faire des courses ou rencontrer les amis. Aucun d'entre eux n'est jamais entré dans l'enceinte de l'Avenida dos Desfiles, ils n'en ont pas besoin m'expliquent-ils: le carnaval ils l'ont vu des dizaines de fois depuis leur fenêtre ! En effet, depuis quelques années, certains d'entre eux sous-louent leur appartement pendant la semaine des Jours Gras, la plupart du temps à des touristes qui souhaitent assister au spectacle sans se fondre dans la foule. Les plans de revitalisation de leur quartier, les actes de «dépatrimonialisation" des biens historiques architecturaux, les tentatives de création de "corridors culturels " voués à dynamiser la vie sociale et économique des alentours... «toutes ces histoires ", me dit Janisio, né il y a quarante-neuf ans derrière l' Avenida Marquês de Sapucai, «on ne les écoute même plus! On n'essaie plus de négocier, avant on allait aux rencontres avec les associations de quartier, d'ici, de Catumbi et autour, on écrivait à la Préfecture, on leur proposait des changements, on leur demandait des places, des parcs pour nos enfants, des lieux pour pouvoir, je sais pas, se réunir, faire des projets (...) maintenant on a compris » (entretien avec Janisio, février 2012). 
Figure 6. À gauche, un char allégorique garé à l'entrée du Sambodrome quelques heures avant la deuxième nuit du carnaval des écoles de samba, le lundi 20 février 2012. Derrière, la tour nord du Balança Mas Nao Cai, l'immeuble « qui tangue mais ne tombe pas ». À droite, entre deux les deux tours du Balança, l'auvent sous lequel se retrouvent certains de ses habitants, pour la plupart membres de la Banda da Praça Onze. Une banderole annonce leur défilé, prévu le 25 février 2012, après le Carnaval Officiel des écoles de samba.

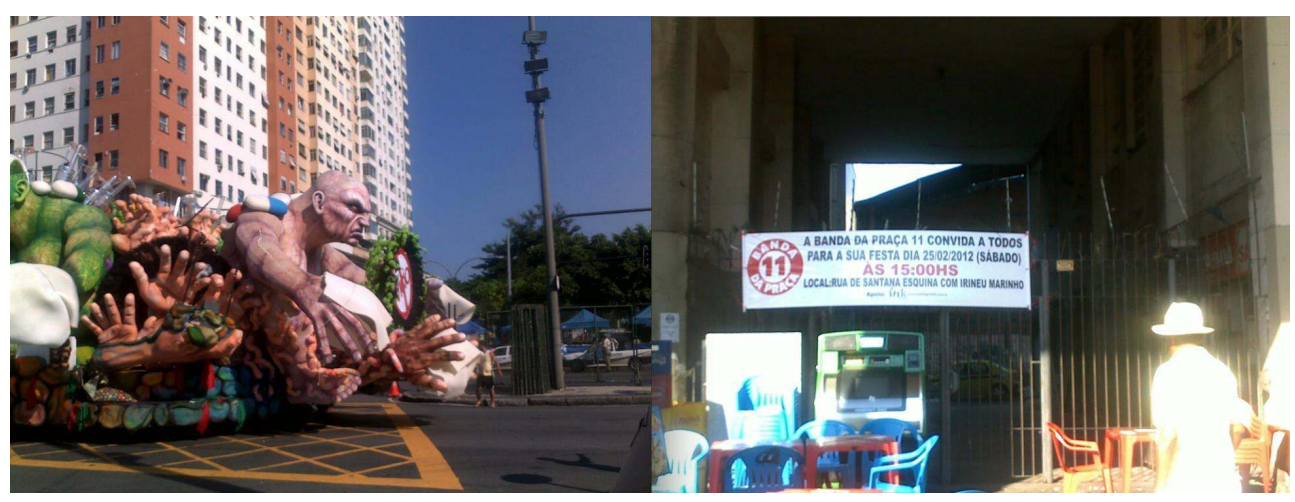

PHOTOS DE L'AUTEURE

Janisio, aidé de ses amis et voisins, a donc conclu que pour revitaliser son quartier, il fallait lui rendre l'aura culturelle dont il ne bénéficiait plus que dans les livres : celle de berceau du carnaval de Rio de Janeiro. Il a donc décidé en 2010 de réactiver une banda, un groupe carnavalesque de quartier formé de percussions et d'instruments de fanfare: la Banda da Praça Onze, qui ne sortait plus dans les rues depuis 1976. Là est le grand paradoxe de la présence du Sambodrome en son quartier : cet immense équipement culturel a été construit à une centaine de mètres de la place publique (la Praça Onze, aujourd'hui détruite) où il y a plus d'un siècle, se concentraient les groupes carnavalesques ancêtres des écoles de samba. Présenté à l'époque de sa construction comme un monumenthommage aux racines du carnaval le plus connu au monde, il est devenu pour ses habitants voisins un barrage urbain les empêchant de faire leur carnaval. Pendant les Jours Gras en effet, toutes les rues environnantes sont transformées en coulisses du « plus grand show de la planète »: impossible pour un petit groupe carnavalesque de quartier de s'y frayer un chemin. Depuis trois ans donc, quelques habitants - pas plus d'une centaine - défilent de nouveau dans le quartier du carnaval. Mais faute d'espace dans les rues bondées autour du Sambodrome, la Banda da Praça Onze ne peut faire son carnaval qu'en dehors du calendrier du carnaval de Rio. Le plus jeune d'entre eux, Marcelo, employé au service culturel de la Préfecture de Rio de Janeiro, caresse l'espoir qu'un jour l'effort de revitalisation urbaine et culturelle dont la zone portuaire est la scène principale s'étende au-delà de la limite administrative de l'Avenida Presidente Vargas. Pour cela, la seule solution serait selon lui de réussir à faire inscrire la "Praça Onze » au patrimoine culturel de l'État de Rio. Toute la difficulté serait alors de déterminer si ce bien serait à considérer au titre du patrimoine immatériel (la Praça Onze n'existe plus, ce serait donc la mémoire du berceau de la samba qu'il faudrait prendre en considération) ou du patrimoine matériel. Dans ce dernier cas, le Sambodrome, après avoir été inscrit au patrimoine culturel de l'Etat de Rio de Janeiro, puis retiré de ses listes en 2011, pourrait les réintégrer non plus comme "noyau d'un patrimoine d'ambiance", mais comme monument qui indique et dissimule tout à la fois le patrimoine mémoriel et culturel de la Praça Onze, ancien cœur de la «Petite Afrique », et «berceau de la samba et du carnaval de Rio de Janeiro ». 


\section{BIBLIOGRAPHIE}

AGIER M. (2000), Anthropologie du carnaval : la ville, la fête et l'Afrique à Bahia, Marseille, Parenthèses.

AUTHIER J.Y. et al (2007), Le quartier : enjeux scientifiques, actions politiques et pratiques sociales, Paris, La Découverte.

BIDOU-ZACHARIASEN C. (2006), De volta à cidade: dos processos de gentrificação às políticas de " revitalização » dos centros urbanos, Sao Paulo, Annablume.

BODEKER H., VEIT P., WERNER M. (2008), Espaces et lieux de concert en Europe, 1700-1920, Berlin, Berliner Wissenschafts-Verlag.

BORDE de LACERDA PESSOA A. (2006), Vazios urbanos: perspectivas contemporâneas, Tese de doutorado - Rio de Janeiro, Universidade Federal do Rio de Janeiro, Programa de Pós-Graduação em Urbanismo.

BRAUDEL F. (1958), « La longue durée », Annales, pp. 725-753.

BRINDLEY T., RYDIN Y., STOKER G. (1996), Remaking Planning, The Politics of Urban Change, London Routledge.

BROMBERGER C. (1995), Le Match de football : Ethnologie d'une passion partisane à Marseilles, Naples et Turin, Paris, Maison des Sciences de l'Hommes.

BROMBERGER C. (2004), Football, la bagatelle la plus sérieuse du monde, Paris, Pocket.

BRUNI F., « Preços do carnaval de 1984. Breve exposiçao das razoes », Pasta I, Arquivos Fundaçao Darcy Ribeiro, Universidade de Brasilia.

CABRAL S. (1996), As escolas de samba do Rio de Janeiro, Rio de Janeiro, Lazuli.

CARDOSO E.D. (1987), História dos Bairros- Saúde, Gamboa e Santo Cristo, Rio de Janeiro, João Fortes Eng.

CARDOSO E.D. (2009), « A invenção da Zona Sul : origens e difusão do topônimo Zona Sul na geografia carioca », GEOgraphia, 11, 22.

CAVALCANTI VIVEIROS de CASTRO M.L. (1999), O rito e o tempo: ensaios sobre carnaval, Rio de Janeiro, Civilização Brasileira.

CHALINE C. (1999), La régénération urbaine, Paris, Presses Universitaires de France.

COSTA H. (2001), 100 anos de Carnaval no Rio de Janeiro, São Paulo, Irmãos Vitale.

DANSERO E., MELA A. (2007), « La territorialisation olympique », Revue de Géographie Alpine 95, 3, pp.5-15

FABRE D. (1992), Carnaval ou la fête à l'envers, Paris, Gallimard.

FERREIRA DOS SANTOS C.N., VOGEL A. (1985), Quando a rua vira casa: A apropriação de espaços de uso coletivo em um centro de bairro, $3^{\text {a }}$ edição, São Paulo, Projeto.

FERREIRA DOS SANTOS C.N. (1981), Movimentos urbanos no Rio de Janeiro, Zahar.

LAMARÃO S. (1991), Dos trapiches ao Porto, Rio de Janeiro, Biblioteca Carioca. 
MAGALHAES R.A. (2008), A Requalificaçao do Centro do Rio de Janeiro, Prefeitura do Rio/Culturas, Coleçao Biblioteca Carioca.

MOURA M. (1986), Carnaval : da Redentora à Praça do Apocalipse, Rio de Janeiro, Zahar.

MOURA R. (1983), Tia Ciata e a Pequena Africa no Rio de Janeiro, Prefeitura do Rio de Janeiro.

MOUTINHO COELHO L. (2009), O Sambodromo da Samba? O impacto de um grande equipamento urnbano na revitalização da Cidade Nova, um bairro do Rio de Janeiro, Mémoire de Master en Architecture et Urbanisme, Universidade de Lisboa.

NIEMEYER O. (1984), « Passarela do Samba », Revista do Brasil, 1, 2, Rio de Janeiro, p. 88.

NIEMEYER O., SUSSEKIND J.C. (1983), « A Passarela do Samba », Módulo, 78, Rio de Janeiro, p.18.

PEREIRA DE QUEIROZ M.I. (1992), Carnaval brésilien : le vécu et le mythe, Paris, Gallimard.

PINHEIRO de FREITAS A.I. (2002), in FREIRE A., LIPPI OLIVEIRA L. (orgs.), Capítulos da memória do urbanismo carioca, depoimentos ao CPDOC/FGV, Rio de Janeiro, Folha Seca.

PREFEITURA DA CIDADE DO RIO DE JANEIRO (2001), Porto do Rio: Plano de Recuperação e Revitalização da Região Portuária do Rio de Janeiro, Rio de Janeiro, SMU/ IPP.

RIBEIRO D. (1968), o processo civilizatorio. Etapas da evoluçao sociocultural, Rio de Janeiro, Companhia das Letras.

RIOTUR (1984), A passarela é uma festa o ano inteiro, Rio de Janeiro, Governo do Estado do Rio de Janeiro.

SALGADO MENEZES L.F. (2001), O "bairro" da Cidade Nova sobre o mangue: ações e limitações do poder público local na área central do Rio de Janeiro, Tese de Doutorado, FAUUSP.

SANSOT P. (2004), Poétique de la ville, Paris, Editions Payot \& Rivages.

SIINO C., LAUMIÈRE F., LERICHE F. (2004), « Métropolisation et grands équipements structurants », Villes et Territoires, 16, Toulouse, Presses Universitaires du Mirail.

SMYTH H. (1994), Marketing the City. The Role of Flagship Developments in Urban Regeneration, Londres, Spon.

TRAJANO J. (1999), Brizolismo. Estetização da política e carisma, Rio de Janeiro, Fundação Getulio Vargas.

TURNER V.W. (1990), Le phénomène rituel. Structure et contre structure, Paris, PUF.

VELHO G. (1989), A utopia urbana, Rio de Janeiro, Zahar.

VIANNA H. (1995), O misterio do Samba, Rio de Janeiro, Zahar.

WERNECK LIMA E.F. (1990), Avenida Presidente Vargas : uma drastica cirurgia, Secretaria municipal de Cultura, Turismo e Esportes, Departamento Geral de Documentaçao e Informaçao Cultural, Rio de Janeiro.

WERNECK SODRÉ N. (1962), Quem é o povo no Brasil ?, Cadernos do Povo Brasileiro.

WERQUIN T. (2008), «L'impact des équipements et évènements culturels sur le développement économique local : entre fantasme et réalité ", Actes du colloque Arts et Territoires : vers une nouvelle économie culturelle?, Québec, 6-7 mai 2008. 


\section{NOTES}

1. Périphrase employée internationalement pour parler de Rio. L'anecdote est peu connue, mais la première plume à l'avoir surnommée ainsi serait celle de Jeanne Nette, deuxième épouse de l'écrivain français Catulle-Mendès. Elle a publié en 1911 un recueil de poèmes intitulé Ville Merveilleuse, au retour d'un séjour de huit mois autour de la Baie de Guanabara.

2. La ala das baianas est une des composantes les plus anciennes du défilé des écoles de samba. Elle fut introduite comme élément obligatoire des défilés en 1930, et tiennent lieu d'hommage aux tias baianas, les "tantes bahianaises", c'est-à-dire les femmes afro-brésiliennes qui dans les quartiers du port du tournant $d u X X^{\text {ème }}$ siècle, avaient un rôle de matriarches de la communauté bahianaise qui s'y était installée. Les fêtes qu'elles organisaient chez elles sont assez largement considérées comme un des «terreaux » ayant rendu possible la constitution de la samba comme un genre musical populaire de Rio de Janeiro. C'est à elles que revient en outre le savoir lié à la purification des lieux (a lavagem) ainsi que la confection de certains plats (comme les acarajés). Voir Moura, 1983.

3. Parmi eux, le journal «A Nova Democracia » et les sites internet du Comité populaire de la Coupe du Monde et des Jeux Olympiques (rio.portalpopulardacopa.org.br) et de l'Observatoire des Métropoles (www.observatoriodasmetropoles.net).

4. De très nombreux ouvrages sont consacrés à l'histoire des «samba-enredo " cariocas, et à la façon dont ils contribuent à forger un imaginaire territorial, local ou national. Parmi les plus connus, celui de la française Monique Augras, vivant au Brésil depuis 1961: O Brasil do Sambaenredo, Fundaçao Getulio Vargas, 1998, et le plus récent Samba de enredo: Historia e Arte, d'Alberto Mussas et Luiz Antônio Simas, Ed. Civilização Brasileira, 2010

5. "Samba-enredo" ou "samba de enredo" est le thème musical chanté pendant le défilé carnavalesque d'une école de samba. Il est écrit et composé après que le directeur de l'école ait annoncé la thématique du défilé (« l'enredo »), par les compositeurs associés à l'école (la ala dos compositores, "l'aile des compositeurs ») ou, de plus en plus souvent, par des compositeurs extérieurs qui circulent d'école en école suivant les années.

6. Le «Grupo Especial» désigne un ensemble composé des douze écoles de samba les plus connues (les mieux notées) de la ville, qui défilent pendant les Jours Gras du Carnaval, dans la nuit du dimanche au lundi, puis dans la nuit du lundi au mardi. Le groupe inférieur rassemblant dix-neuf écoles au succès moindre s'appelle le « Grupo de Acesso ».

7. De très nombreux ouvrages sont consacrés à l'histoire des «samba-enredo » cariocas, et à la façon dont ils contribuent à forger un imaginaire territorial, local ou national. Parmi les plus connus, celui de la française Monique Augras, vivant au Brésil depuis 1961: O Brasil do Sambaenredo, Fundaçao Getulio Vargas, 1998, et le plus récent Samba de enredo: Historia e Arte, d'Alberto Mussas et Luiz Antônio Simas, Ed. Civilização Brasileira, 2010.

8. C'est le cas des blocos inscrits à la Desliga dos blocos cariocas, un collectif informel qui milite pour la préservation de la spontanéité de carnaval de rue, et contre le décret n³2664 de la Préfecture de Rio obligeant les groupes carnavalesques à envoyer une demande d'autorisation de déambulation six mois avant le carnaval.

9. O povo: au Brésil le terme de "peuple» fait partie du vocabulaire quotidien et recouvre des réalités à géométries fortement variables. Pour une histoire critique du concept de « peuple » au Brésil, voir Werneck Sodré, 1962.

10. Ce que Turner appelle la « reclassification sociale périodique » dirigée vers une «supériorité structurale imaginaire » des plus faibles (Turner, 1990, p. 163). À ce titre, l'on peut se demander s'il est encore légitime d'étudier le défilé des écoles de samba en tant que rituel carnavalesque (Agier, 2000, p. 231). Quelle dialectique le carnaval des écoles de samba opère-t-elle encore? 
Renvoie-t-il encore à quelque chose d'autre qu'à lui-même? Sur la question de la frontière entre le rituel et le spectacle, voir en particulier l'analyse de Christian Bromberger sur les matches de football (Bromberger, 1995 et 2004).

11. Rappelons ici que le verbe «transgresser» vient du latin transgressio, «marcher au travers, au-delà ».

12. Le territoire s'étendant de la zone portuaire jusqu'au quartier de la Cidade Nova (où est situé aujourd'hui le Sambodrome) avait été surnommé ainsi par le sambista Heitor dos Prazeres, dans les années 20. Ces quartiers du centre historique et du port abritaient la plus importante communauté bahianaise de la ville, anciens esclaves et descendants libérés en 1888 dans la région de Bahia (Nord-est du Brésil), descendus à Rio pour trouver du travail dans la capitale en pleine expansion. L'expression de "Petite Afrique » est actuellement remise au goût du jour dans les quartiers du port, à travers les nombreux projets culturels de valorisation du patrimoine culturel " afro-brésilien » de Rio. Des « Circuits historiques et archéologiques de célébration de l'héritage africain de Rio » sont organisés plusieurs fois par semaine, plusieurs fois par jour en période de carnaval. (cf. www.portomaravilha.com.br)

13. Interview pour le journal 0 Globo, 23 janvier 1984.

14. Fluminense: de l'État de Rio de Janeiro.

15. entre 1000 et $1800 \%$ d'augmentation du prix des billets d'entrée entre le carnaval de 1983 et celui de 1984, pour des montants allant de l'équivalent de 7 euros à presque 600 euros l'unité. Cf. aux archives du Centre Darcy Ribeiro, Universidade de Brasilia ; «preços do carnaval de 1984. Breve exposiçao de razoes ", Franco Bruni, Pasta I.

16. Lettre d'Oscar Niemeyer à Leonel Brizola, Rio de Janeiro, 6 février 1985. Pasta 1 caixa 26, Fundaçao Darcy Ribeiro, Universidade de Brasilia

17. Je tiens cette information d'une conversation avec Cristina, directrice d'un des CIEPS de l' Avenida dos Desfiles., datant de juillet 2010.

18. «Sambodromo no Rio nao tera mais CIEPS e creches ", Antero Gomes, journal Extra du 22 novembre 2010.

19. A ce jour je n'ai eu connaissance que de deux travaux s'intéressant à l'implantation du Sambodrome dans le territoire de la Cidade Nova et du Centro: celui d'Andréa Borde qui a consacré sa thèse de doctorat d'urbanisme aux vides urbains, notamment ceux de la zone portuaire et de la zone Centre de Rio (Borde, 2006), et celui de Luciane Moutinho Coelho qui y a consacré son mémoire de Master en architecture et urbanisme (Moutinho Coelho, 2009).

20. Pour une réflexion interdisciplinaire sur le quartier et les « effets de quartier ", voir Authier et al., 2007.

21. Il est fréquent de lire dans la bibliographie brésilienne ou d'entendre parler de « chirurgies urbaines » pour désigner les multiples plans de rénovation échafaudés depuis le tournant du XX ème siècle dans le centre historique et la zone portuaire de Rio, et plus largement les opérations de destructions massives de quartiers populaires urbains et de reconstructions non intégrées de grands équipements. Pour une étude historique de la plus importante «chirurgie urbaine » de la région (du moins jusqu'à aujourd'hui), voir Werneck, 1990.

22. Par ordre chronologique, les stations « Central », « Estacio » et « Praça Onze ». 


\section{RÉSUMÉS}

Depuis que la ville de Rio de Janeiro a été nommée ville d'accueil des Jeux Olympiques de 2016, toutes les attentions se tournent vers sa zone portuaire, actuellement en voie de reconversion après une trentaine d'années durant lesquelles les anciens hangars industriels inoccupés avaient laissé place à des hectares de friches et de vides urbains. A Rio comme dans d'autres métropoles portuaires mondiales ayant été les scènes de programmes de revitalisation similaires, la segmentation de l'espace urbain par territoires-projets participe à un surinvestissement médiatique et politique de certains quartiers, et à un désinvestissement de ceux qui ne font pas partie du cadastre du changement urbain. C'est le cas du quartier du Sambodrome de Rio de Janeiro, cette grande avenue bordée de gradins accueillant chaque année les défilés des meilleures écoles de samba de la ville, et leurs soixante-dix mille spectateurs. Construit sur un territoire tenu pour être le berceau de la samba et du carnaval de Rio de Janeiro, le Sambodrome et ses alentours ont toujours été désinvestis de la pensée aménagiste et des programmes culturels et patrimoniaux menés par la Ville de Rio de Janeiro et son État. A partir d'une enquête ethnographique menée en 2011 et 2012 pendant les travaux du " Nouveau Sambodrome ", je propose dans cet article de replacer ce «très grand équipement culturel » dans la topographie musicale et festive de Rio de Janeiro, et de questionner son impact sur la vie quotidienne et la mémoire culturelle de son quartier d'implantation.

Since Rio de Janeiro has been elected host city for the next Olympic Games in 2016, an increased attention is pointed on its docks, currently in the full heart of an urban reconversion after about thirty years of desertion which have left hectares of industrial wasteland and empty urban spaces. In Rio, as well as in other harbour cities in the world which have been the scenes for similar revitalization programs, the segmentation of the urban space by projects has led to a media and political overinvest of some districts, and to a disinvestment of the ones which don't belong to the limits of the urban change planning. It is the case of the Sambodromo's district, this huge avenue receiving each year the samba schools parade and about 70,000 spectators. Constructed in the territory known as the birthplace of samba and Rio carnival, the Sambodromo and its district have always been very little invested from the urban planning as well as from the cultural and patrimonial public programmes. From an ethnographic inquiry conducted in 2011 and 2012 during the construction works of a "New Sambodromo ", I propose in this article to replace this cultural equipment in the musical and festive topography of Rio, and to question its impact onto the social and cultural life of its district.

\section{INDEX}

Mots-clés : Rio de Janeiro, Sambodrome, Carnaval, samba, Praça Onze, mémoire culturelle

Keywords : Rio de Janeiro, Sambodrome, Carnival, samba, Praça Onze, cultural heritage 


\section{AUTEUR}

\section{LAURA JOUVE-VILLARD}

Doctorante en Musique, Histoire et Société, Centre Georg Simmel/EHESS, jvlaura@gmail.com 